\title{
Ionic Conductances Underlying the Activity of Interneurons That Control Heartbeat in the Medicinal Leech
}

\author{
Edmund A. Arbas and Ronald L. Calabrese ${ }^{a}$ \\ Biological Laboratories, Harvard University, Cambridge, Massachusetts 02138
}

\begin{abstract}
Electrical properties of interneurons that control heartbeat in the leech (HN cells) were studied using intracellular recording and stimulation in isolated ganglia bathed by salines of various ionic compositions. Substitution of $\mathrm{Na}^{+}$ions in the bath by Tris stopped the spontaneous firing of $\mathrm{HN}$ cells and led to their gradual hyperpolarization by 15-20 mV. In the absence of $\mathrm{Na}^{+}$, HN neurons produced long-lasting regenerative plateau potentials with thresholds near $-55 \mathrm{mV}$ and peaks near $-30 \mathrm{mV}$ that were accompanied by an increase in membrane conductance. Elevation of $\mathrm{Ca}^{2+}$ concentration enhanced plateaus, as did replacement of $\mathrm{Ca}^{2+}$ by $\mathrm{Ba}^{2+}$. Plateaus were formed when $\mathrm{Sr}^{2+}$ replaced $\mathrm{Ca}^{2+}$, but were blocked by addition of $\mathrm{Mg}^{2+}$ or $\mathrm{Co}^{2+}$ to the bath, $\mathrm{Co}^{2+}$ being effective at lower concentrations than $\mathbf{M g}^{2+}$. Hyperpolarization of HN neurons with injected currents revealed a timedependent change in membrane potential, whereby initial maximum hyperpolarization was followed by a "sag" in potential towards more depolarized values. The sag showed dual voltage dependence, being diminished when HN neurons were hyperpolarized or depolarized outside the normal range of oscillation. The sag was found to depend on the presence of $\mathrm{Na}^{+}$ions and to be blocked by $\mathrm{Cs}^{+}$but not by $\mathrm{Ba}^{2+}$. This time-dependent change in membrane potential counters hyperpolarizations of HN neuron membrane potential and may contribute to the escape of these neurons from synaptic inhibition.
\end{abstract}

Three classes of central neurons are primarily involved in controlling heartbeat in the medicinal leech. The first class comprises a network of 14 identified heart interneurons (HN cells), generates the heartbeat rhythm, and controls the activity of the second class, excitatory heart motor neurons (HE cells) (Thompson and Stent, 1976b, c; Calabrese and Peterson, 1983). The latter group of neurons delivers the centrally derived activity to heart muscle in the periphery and sets the timing and intersegmental coordination of constrictions in the tubular hearts (Thompson and Stent, 1976a; Maranto and Calabrese, 1984a, b). A third class, the heart accessory (HA) neurons also receive input from the $\mathrm{HN}$ interneurons and function to modulate the myogenic properties and contractile strength of heart muscle cells (Calabrese and Maranto, 1984).

\footnotetext{
Received Dec. 11, 1986; revised May 11, 1982; accepted June 5, 1987.

Supported by an NIH postdoctoral fellowship, 5 F32 NS 06453 (to E.A.A.) and NIH Grant NS 24072 (to R.L.C.)

Correspondence should be addressed to Edmund A. Arbas, Arizona Research Laboratories, Division of Neurobiology, 611 Gould-Simpson Science Building, University of Arizona, Tucson AZ 85721 .

a Present address: Department of Biology, Emory University, 1555 Pierce Drive, Atlanta, GA 30322.

Copyright (C) 1987 Society for Neuroscience $027 U-6474 / 87 / 123945-08 \$ 02.00 / 0$
}

The synaptic relations of $H N$ neurons among themselves, and with $\mathrm{HE}$ and HA neurons are known. Many of the properties of individual neurons and the circuit interactions within the pattern generator that cooperate to form the rhythm for heartbeating have been characterized (e.g., see Calabrese and Peterson, 1983, for review). We report here on several intrinsic cellular properties that underly the electrical activity of $\mathrm{HN}$ interneurons revealed by making intracellular recordings from isolated ganglia bathed in salines of various ionic compositions.

\section{Materials and Methods}

Leeches, Hirudo medicinalis, were obtained from European suppliers and were maintained at $15-20^{\circ} \mathrm{C}$ without feeding for up to 4 months before use.

All intracellular recordings were made at room temperature with standard microelectrodes filled with $4 \mathrm{M}$ potassium acetate. Currents were injected into neurons via a bridge circuit that allowed the simultaneous recording of membrane potential.

Dissections and standard recordings were performed with the preparation bathed in physiological saline (Nicholls and Baylor, 1968) containing (mM) $115 \mathrm{NaCl}, 4 \mathrm{KCl}, 1.8 \mathrm{CaCl}_{2}, 10$ glucose, and 10 Tris buffer adjusted to $\mathrm{pH}$ 7.4. For physiological salines with altered divalent cation concentrations, the chloride salt of each ion replaced equal osmolar amounts of $\mathrm{NaCl}$ in the normal saline. In some solutions, all or part of the $\mathrm{Na}^{+}$was replaced with Tris(hydroxymethyl)aminomethane (Sigma).

Bilateral pairs of $\mathrm{HN}$ interneurons are located in the 7 most proximal segmental ganglia and are indexed according to ganglion number and side [e.g., HN $(\mathrm{L}, 1)$. . HN $(\mathrm{R}, 7)]$. HE motor neurons are located in the 3 rd through 18 th segmental ganglia and are similarly indexed. Experiments with $\mathrm{HN}$ interneurons were made on isolated $3 \mathrm{rd}$, 4th, or 7 th segmental ganglia. The connections among the $\mathrm{HN}$ interneurons and with $\mathrm{HE}$ motor neurons are summarized in Figure $1, A$ and $B$. In ganglia 3 and 4, contralateral $\mathrm{HN}$ neurons are coupled by strong reciprocal inhibitory connections, while there is no synaptic communication between the bilateral HN (7) neurons (Thompson and Stent, 1976c; Calabrese and Peterson, 1983). Each of the HN (3) neurons also makes an inhibitory synaptic connection with the ipsilateral $\mathrm{HE}$ motor neuron of its own ganglion, while neither $\mathrm{HN}$ (4) nor $\mathrm{HN}$ (7) neurons communicate with HE motor neurons of their own ganglia (Thompson and Stent, $1976 \mathrm{~b})$. HN neurons of the first 4 ganglia generate the heartbeat rhythm and thus comprise the timing oscillator of the system, while the HN neurons of the 5 th- 7 th ganglia are responsible for controlling intersegmental phasing of the motor pattern (Calabrese and Peterson, 1983). All premotor $\mathrm{HN}$ interneurons communicate synaptically with $\mathrm{HE}$ motor neurons of more posterior ganglia via their caudally projecting axons (Fig. 1A). Although the HN (7) interneurons receive descending inputs from the HN (5) interneurons, they do not feed back onto these cells. Thus, their activity is uncomplicated by the reverberations that usually appear in $\mathrm{HN}$ interneurons of the timing oscillator when they are stimulated with injected currents.

\section{Results}

Normal activity

The normal activity of $\mathrm{HN}$ interneurons and $\mathrm{HE}$ motor neurons is illustrated in Figure $1 \mathrm{C}$. $\mathrm{HN}$ interneurons produce bursts of 

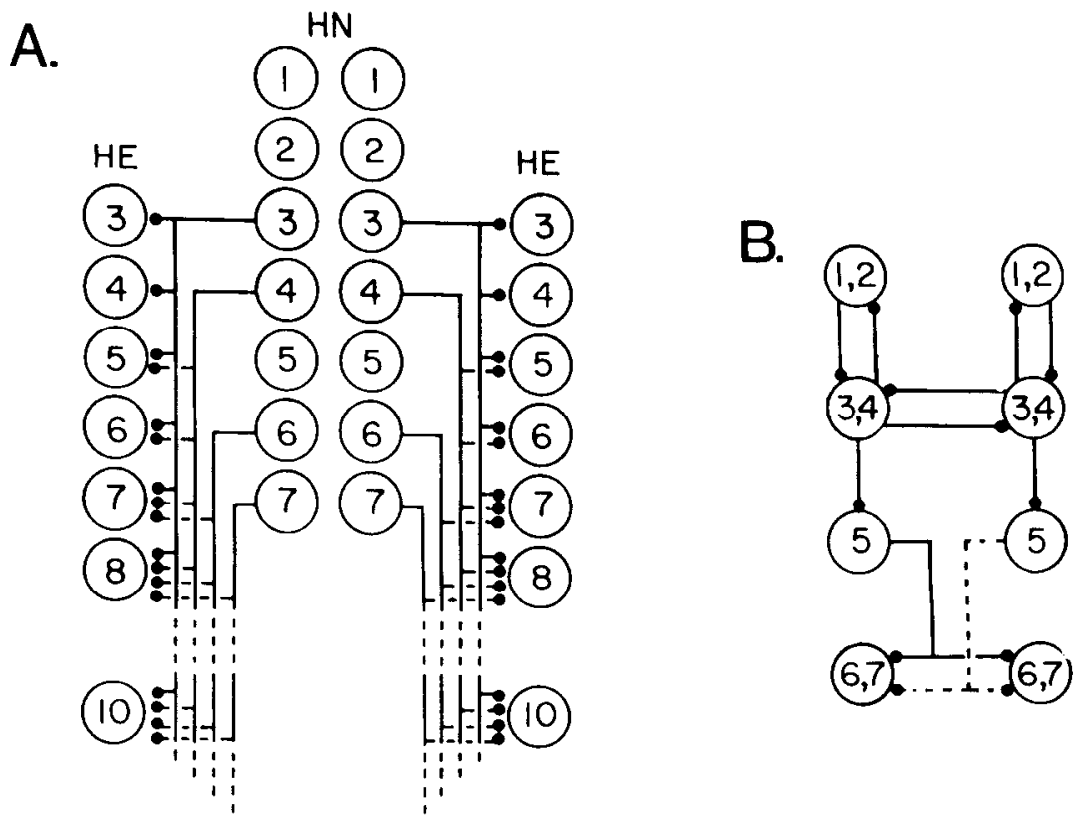

Figure 1. Synaptic connectivity in the heartbeat central pattern generator. $A$, Schematic showing the inhibitory synapses from identified premotor $\mathrm{HN}$ interneurons to HE motor neurons. Open circles represent neurons (each identified by the number of its ganglion) and lines represent their processes, while filled circles denote inhibitory chemical synapses. $B$, Schematic showing all of the inhibitory synapses among the identified HN interneurons. HN cells with similar inputs, outputs, and properties are lumped together. $C$, Simultaneous intracellular recordings showing the normal activity of 2 reciprocally inhibitory $\mathrm{HN}$ interneurons of the timing oscillator [HN (4)] and an HE moto neuron $[\mathrm{HE}(\mathrm{R}, 5)]$ innervated by one of them. The dashed lines in this and all subsequent records indicate a membrane potential of $-50 \mathrm{mV}$.

C.

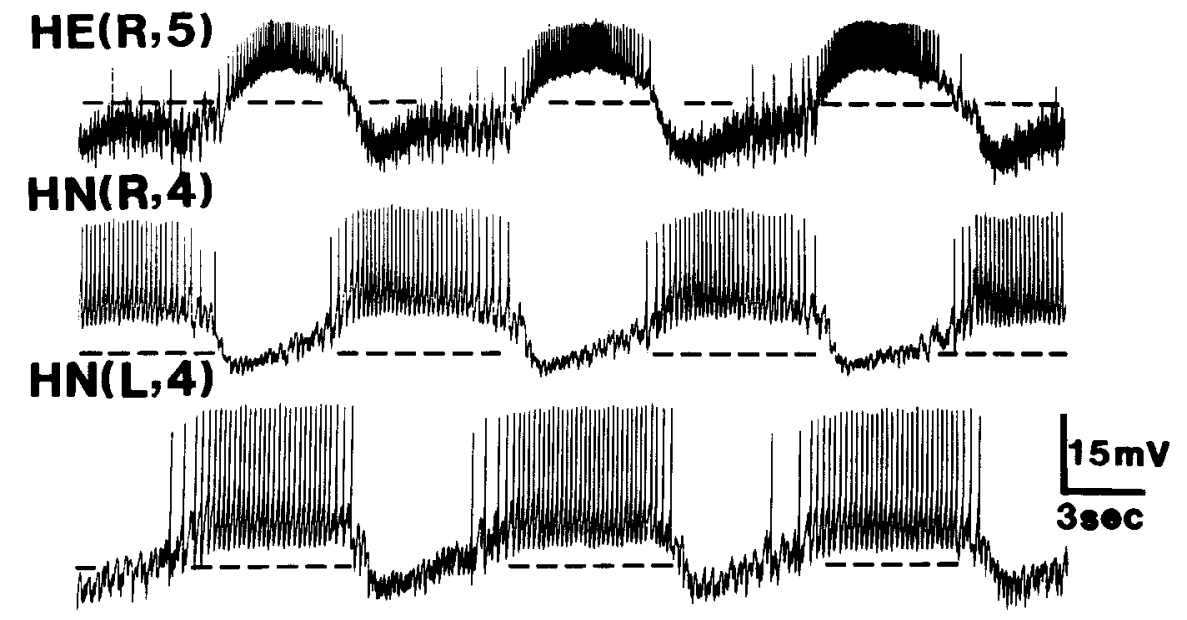

action potentials riding atop slow oscillations of up to $10 \mathrm{mV}$ amplitude centered around a value near $-47 \mathrm{mV}$. HN cell firing is interrupted by barrages of IPSPs caused by the firing of other HN interneurons within the network (Thompson and Stent, 1976c; Calabrese and Peterson, 1983) (Fig. 1C). When these inhibitory connections are blocked by removal of $\mathrm{Cl}$ from the saline bathing the ganglion, HN interneurons, excluding $\mathrm{HN}$ (5), continue to burst, although at a higher rate and without the normal coordination with respect to each other (Calabrese, 1979). Recorded from somata, the action potentials of $\mathrm{HN}$ interneurons are larger than those of HE motor neurons, ranging from 15 to $40 \mathrm{mV}$ in amplitude in different preparations.

\section{Properties of $H N$ interneurons}

Depolarization and hyperpolarization of HN neurons with injected currents revealed several properties not immediately evident from observations of their ongoing spontaneous activity. These are demonstrated for an HN (7) interneuron in Figure 2. Short depolarizations from "rest potential" (near $-40 \mathrm{mV}$ ) triggered high-frequency firing of fast action potentials. When sim- ilar pulses were superimposed on a more hyperpolarized membrane potential maintained by injected current, slowly rising and prolonged "plateau" depolarizations capped by fast action potentials were elicited. When the $\mathrm{HN}$ interneuron was released from hyperpolarization, a plateau response was generated in which the membrane potential depolarized above the rest level and held briefly at near $-30 \mathrm{mV}$ after the production of several action potentials. This was followed by a progressive decline of baseline potential and action potential firing frequency to resting levels over the following several seconds. Reduction in the membrane potential displacements caused by the continuing injection of constant-current pulses indicated that a conductance increase accompanied the plateau.

\section{Contributions of $\mathrm{Na}^{+}$and $\mathrm{Ca}^{2+}$ to activity of $\mathrm{HN}$ interneurons}

The contributions of $\mathrm{Na}^{+}$and $\mathrm{Ca}^{2+}$ to $\mathrm{HN}$ interneuron activity were tested by bathing ganglia with salines in which the appropriate cations were replaced by impermeant substitutes or to 


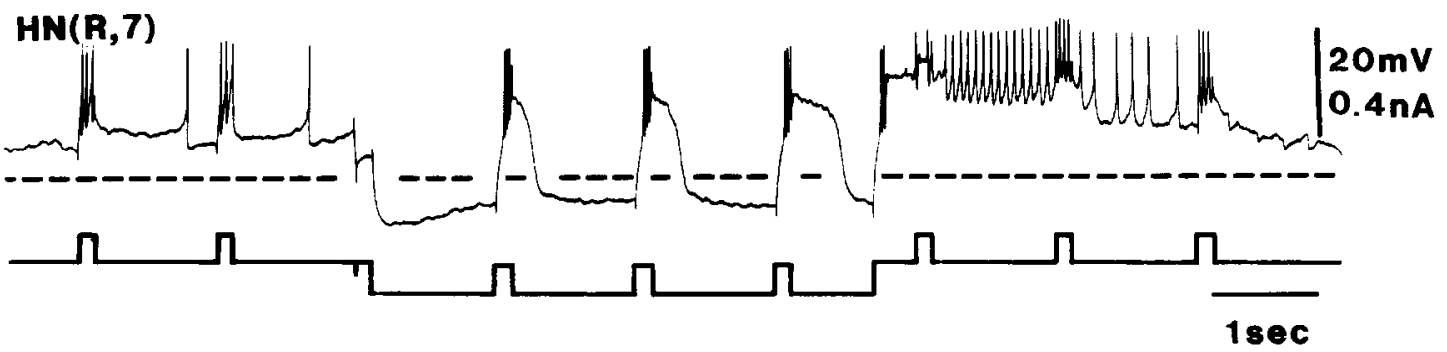

Figure 2. Responses of an $\mathrm{HN}(\mathrm{R}, 7)$ interneuron to constant-current pulses injected at rest and hyperpolarized membrane potentials. The preparation was bathed in normal saline. Depolarizations from rest elicited spiking. Similar depolarizations from a more hyperpolarized level of membrane potential triggered plateau depolarizations capped by fast action potentials. Release from hyperpolarization similarly activated a prolonged depolarization topped by fast spikes.

which blockers of certain ionic currents were added (see Materials and Methods).

Replacement of $50 \%$ of the $\mathrm{Na}^{+}$(leaving $\left[\mathrm{Na}^{+}\right]=57 \mathrm{~mm}$ ) reduced the spontaneous firing frequency of $\mathrm{HN}$ interneurons as well as the amplitude of their action potentials (by about 5 $\mathrm{mV}$ ) after several minutes exposure (Fig. 3, $A$ and $B$ ). Fewer action potentials were produced during the initial second of the plateau response, while the plateau depolarization reached a more depolarized level than in normal saline (Fig. $3 B$ ). This apparent enhancement of the plateau was likely due to the lack of its degradation by afterpotentials of superimposed spikes. Production of action potentials failed after several minutes of washing in $25 \% \mathrm{Na}^{+}$saline $\left(\left[\mathrm{Na}^{+}\right]=29 \mathrm{mM}\right)$, though the plateau depolarization was still generated (Fig. 3 C). Replacement of $\mathrm{Na}^{+}$ with Tris also led to the gradual hyperpolarization of rest potential by $15-20 \mathrm{mV}$ in every experiment of this type. Plateaus continued to be formed in $\mathrm{Na}^{+}$-free salines (Fig. $3 D$ ), until the membrane potential hyperpolarized below about $-55 \mathrm{mV}$ (Fig. $3 E$ ). Plateau potentials could be induced by hyperpolarizing pulses in the continuing absence of $\mathrm{Na}^{+}$in this and other similar preparations by depolarizing the $\mathrm{HN}$ cell above $-55 \mathrm{mV}$ with injected currents (Fig. $4 A$ ) or by adding small amounts of $\mathrm{Na}^{+}$ back to the bath, a treatment that caused gradual depolarization of the baseline membrane potential into a range suprathreshold for the expression of the plateaus.

Injecting current pulses during platcau formation in $\mathrm{Na}^{+}$-frec salines indicated that a marked conductance increase coincides with the peak of the plateau (Fig. $4 B$ ). Since the conductance increase occurs in the absence of external $\mathrm{Na}^{+}$, a likely candidate for the ion mediating this plateau potential is $\mathrm{Ca}^{2+}$

\section{Effects of elevated $\mathrm{Ca}^{2+}$ concentration and the presence of other divalent ions}

The role of $\mathrm{Ca}^{2+}$ in plateau formation was investigated by altering divalent ion concentrations in the bath. The most commonly observed effects on the plateau potential of raising $\mathrm{Ca}^{2+}$ concentration are illustrated in Figure 5. In this example, plateaus were triggered with hyperpolarizing pulses in an HN (7) neuron kept at plateau threshold with a small injected bias current and bathed in Na-free saline containing $1.8 \mathrm{mM} \mathrm{Ca}^{2+}$ (Fig. $5 A$ ). Then the bath was replaced with salines containing progressively higher concentrations of $\mathrm{Ca}^{2+}$ (Fig. 5B-D). Raising $\mathrm{Ca}^{2+}$ concentrations initially caused broadening of the plateau and then, at higher concentration, brought on the production of slow action potentials. At first, these preceded prolonged plateaus; then, later bursts of these slow regenerative potentials replaced the plateau (Fig. $5 D$ ). If $\mathrm{Ca}^{2+}$ was elevated to $20 \mathrm{~mm}$ / liter in presence of normal $\mathrm{Na}^{+}, \mathrm{HN}(7)$ interneurons produced bursts of fast action potentials atop the slower $\mathrm{Ca}^{2+}$-mediated potentials on release from imposed hyperpolarization.

$\mathrm{HN}$ interneurons sustained long plateau depolarizations in the presence of $\mathrm{Ba}^{2+}$ or $\mathrm{Sr}^{2+}$ (Fig. 6) but not in $\mathrm{Co}^{2+}$ or $\mathrm{Mg}^{2+}$. Action potentials could be elicited by current injection in the presence of the latter 2 ions if $\mathrm{Na}^{+}$was also present in the saline (Fig. $7 D$ ). $\mathrm{Mg}^{2+}$ concentrations of $30 \mathrm{~mm}$ or greater were required to eliminate the plateau potentials. Lower concentrations reduced the amplitude of the plateau and shifted its threshold potential to more depolarized values. The threshold potential of the fast spikes was also shifted to more depolarized values in a manner consistent with the membrane-stabilizing effects of divalent ions (Frankenhaeuser and Hodgkin, 1957). By contrast, $10 \mathrm{~mm} \mathrm{Co}^{2+}$ rapidly eliminated the plateau (Fig. 7, $B$ and $C$ ).

\section{Restorative shifts in membrane potential}

A property exhibited by HN neurons that seems to be of great importance to their normal activity patterns appears as a timedependent change in the membrane potential during injection of long hyperpolarizing currents of the type used in this study to trigger plateaus (e.g., Fig. 3, $A$ and $B$ ). On injection of a constant-current hyperpolarizing pulse, the membrane potential of an HN interneuron exhibits an initial maximum hyperpolarization followed by a sag to more depolarized levels over timc. This sag sccms thus to opposc hypcrpolarizations of mcmbrane potential and tends to depolarize the membrane potential whenever it is hyperpolarized. Our studies indicate that the sag in membrane potential in HN neurons is complex in nature and has the following properties: (1) It is insensitive to blockers of $\mathrm{Ca}^{2+}$ conductances (e.g., Fig. 7). This reduces the likelihood that the sag in membrane potential is due to possible voltage-dependent termination of $\mathrm{Ca}^{21}$ current and any associated $\mathrm{Ca}^{2+}$ dependent $\mathrm{K}^{+}$current during the hyperpolarizing pulse. (2) The sag in membrane potential exhibits voltage dependence, becoming reduced at membrane potentials more depolarized than a narrow range near rest, and also as the membrane potential is hyperpolarized (Fig. 8). (3) The sag has a strong dependence on $\mathrm{Na}^{+}$and is diminished as $\mathrm{Na}^{+}$is replaced by Tris (Fig. 3). (4) The sag in membrane potential was found to be sensitive to blockade by $\mathrm{Cs}^{+}$, but not, under similar conditions, by $\mathrm{Ba}^{2+}$ (Fig. 9).

\section{Properties of $H N$ interneurons of the timing oscillator}

Most of the examples of HN cell activity thus far shown were obtained from HN interneurons of ganglion 7. HN interneurons of ganglia 3 and 4 (i.e., timing oscillator interneurons) exhibit 


\section{HN 7}
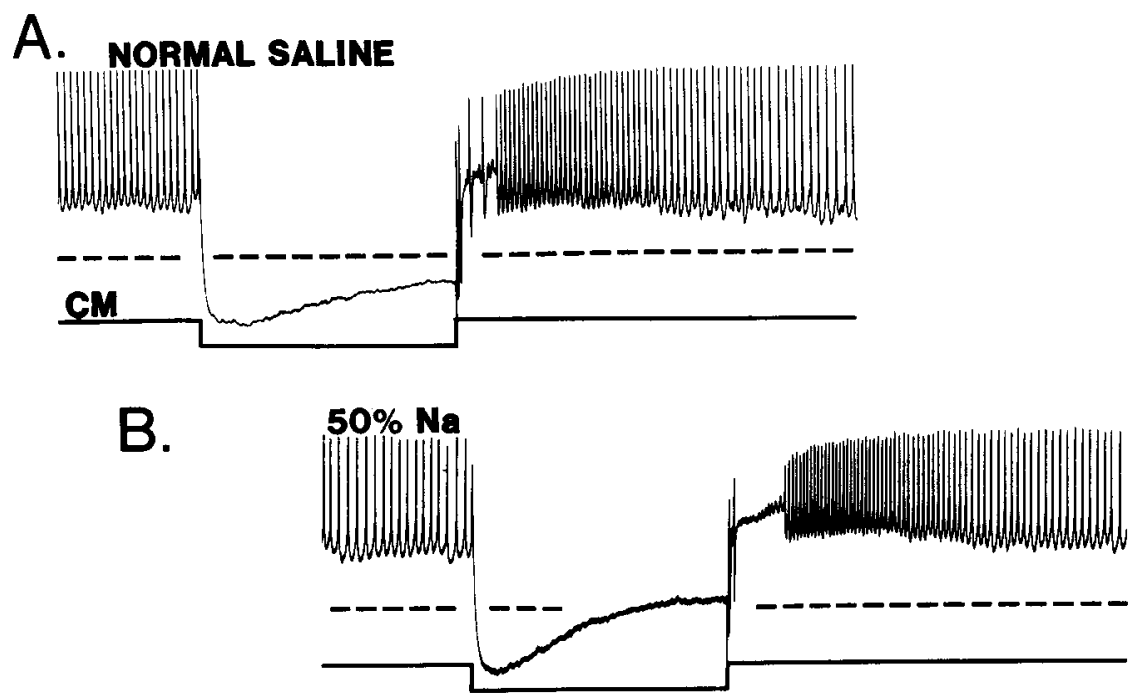

\section{$20 \mathrm{mV}$ \\ $1.2 \mathrm{nA}$ \\ 3 sec}
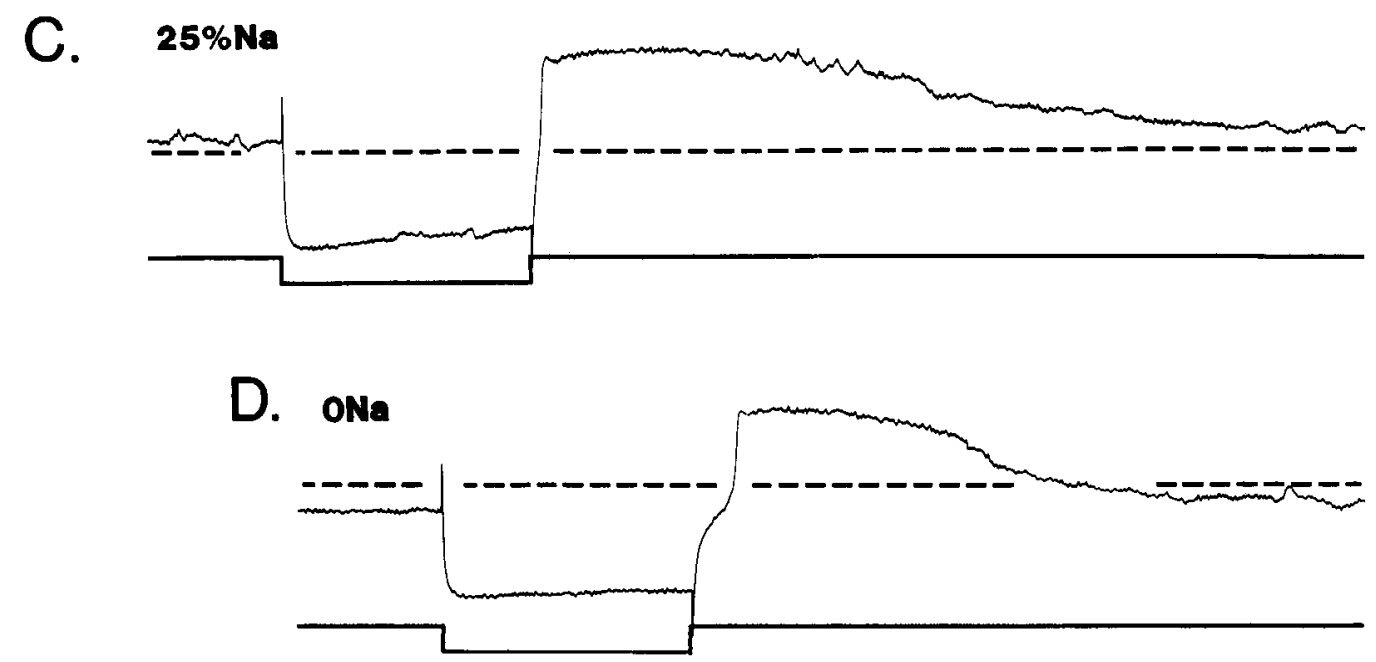

\section{E. ONa}

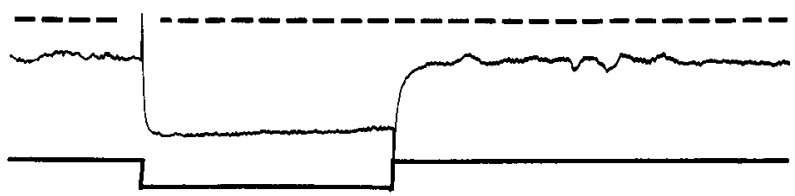

Figure 3. Plateau depolarizations occur in low- $\mathrm{Na}^{+}$and $\mathrm{Na}^{+}$-free salines. Hyperpolarizing square pulses were injected into an $\mathrm{HN}(7)$ interneuron, while salines in which Tris replaced different amounts of $\mathrm{Na}^{+}$washed the ganglion. All salines contained $1.8 \mathrm{~mm} \mathrm{Ca}{ }^{2+} . A$, Plateau formation in an HN (7) neuron in normal saline. B, Firing frequency and spike amplitude were reduccd following scveral minutes in saline with $50 \%$ of the Na ${ }^{+}$ replaced by Tris. $C$, No fast action potentials were produced following several minutes of washing in saline containing $25 \%$ of normal $\mathrm{Na}^{+}$, although the plateau continued to be formed. Throughout the series, the HN neuron gradually hyperpolarized as $\mathrm{Na}^{+}$content of the saline was reduced. $D$, The plateau response continued to be formed in $\mathrm{Na}^{+}$-free saline until, $E$, the $\mathrm{HN}$ interneuron hyperpolarized to a value below $-55 \mathrm{mV}$. $C M$, current monitor.

all of the properties described for HN (7) interneurons and have the additional characteristic that they are connected in oscillatory circuits (Thompson and Stent, 1976c; Calabrese and Peterson, 1983). Oscillations in membrane potential occurred in the bilateral HN interneurons of ganglia 3 or 4 in the presence of elevated $\mathrm{Ca}^{2+}$ that were based on the alternate production of the long-lasting plateau depolarizations and reciprocal inhibitory transmission between the contralateral $\mathrm{HN}$ neurons. A more 

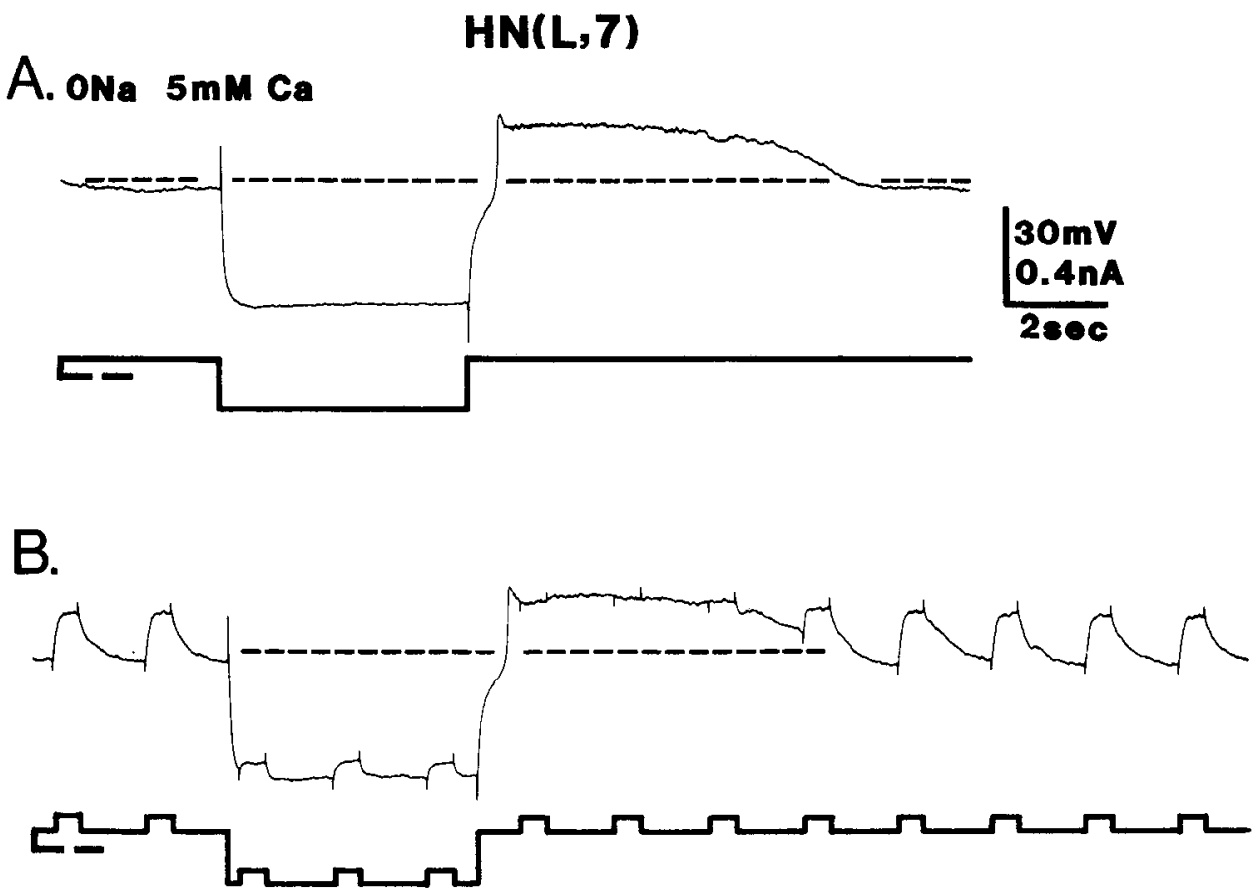

Figure 4. Conductance increase accompanies plateau formation in $\mathrm{Na}^{+}$free saline. $A$, Plateau was formed on release from hyperpolarization in an $\mathrm{HN}$ (7) neuron bathed by $\mathrm{Na}^{+}$-free saline and depolarized above $-55 \mathrm{mV}$ by an injected bias current. $B$, Short, constant-current pulses injected during a similar recording show that a substantial increase in conductance coincides with the peak of the plateau. Dashed lines associated with the current traces indicate zero injected current. The short pulses had an amplitude of $0.05 \mathrm{nA}$.

detailed treatment of the oscillations of timing oscillator interneurons is presented in a separate report (Arbas and Calabrese, 1987).

\section{Discussion}

The present study indicates a rich complexity in the ionic mechanisms underlying the activity of HN interneurons. This activity is characterized by the production of bursts of action potentials alternating with hyperpolarized silent periods dominated by inhibitory synaptic input. By recording from $\mathrm{HN}$ interneurons under altered ionic conditions, we have identified several cellular properties that contribute to this activity.

Removal of $\mathrm{Na}^{+}$from the saline solution stopped the spontaneous firing of HN cells and eliminated the capability of injected current pulses to elicit fast action potentials. This suggests that $\mathrm{Na}^{+}$is the primary charge carrier during fast action potentials in each $\mathrm{HN}$ cell burst.

In the absence of $\mathrm{Na}^{+}$action potentials, $\mathrm{HN}$ neurons continued to produce long-lasting regenerative plateau potentials on release from injected hyperpolarizing current pulses. Plateaus were found to be accompanied by an increase in membrane conductance and were enhanced in the presence of elevated $\mathrm{Ca}^{2+}$ concentrations or $\mathrm{Ba}^{2+}$ or $\mathrm{Sr}^{2+}$ but blocked by $\mathrm{Mg}^{2+}$ or $\mathrm{Co}^{2+}$. These observations suggest that a voltage-dependent $\mathrm{Ca}^{2+}$ conductance mediates plateau formation in the absence of $\mathrm{Na}^{+}$. Voltage-dependent $\mathrm{Ca}^{2+}$ currents have previously been shown to underly activity recorded from the somata of a number of neurons in the leech (Kleinhaus and Prichard, 1977) and may indeed be a property of all neuron somata in all organisms (Hagiwara and Byerly, 1981).

Injection of hyperpolarizing square pulses into $\mathrm{HN}$ neurons revealed a time-dependent restorative sag in membrane potential that depolarizes HN cells whenever they are hyperpolarized. Several kinds of conductances have been shown to contribute to similar properties in other neurons. A reduction of voltagedependent $\mathrm{K}^{+}$conductance, the "M-current," produces sags in membrane potential following injection of hyperpolarizing current pulses in a number of vertebrate neuron types (Adams et al., 1982). A similar waveform has been shown to result from the activation of inward currents on hyperpolarization in a number of preparations, including mammalian and amphibian cardiac cells (DiFrancesco, 1985); mammalian hippocampal pyramidal neurons (Adams and Halliwell, 1982; Halliwell and Adams, 1982), olfactory cortical neurons (Constanti and Gal-

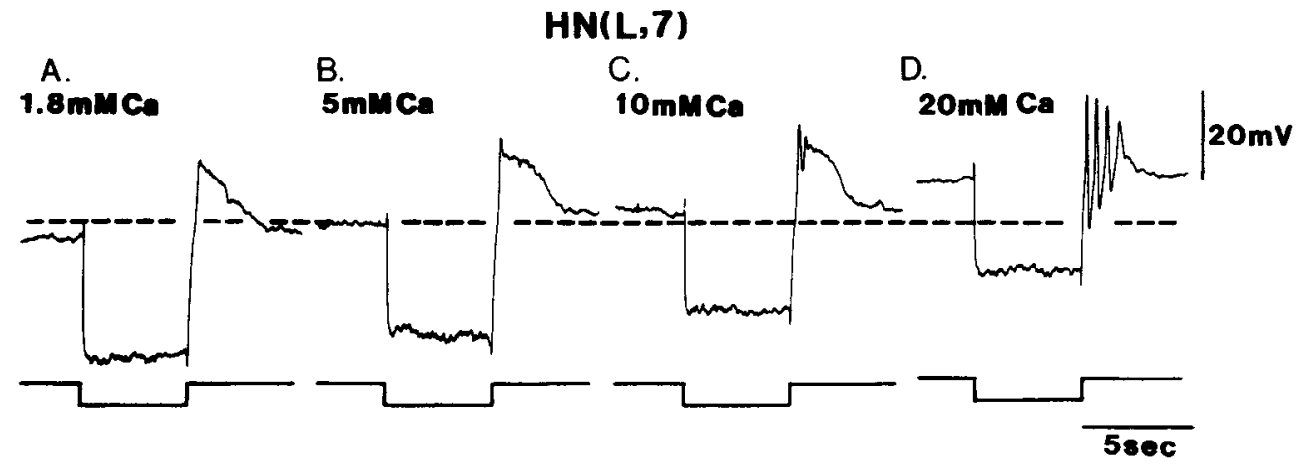

Figure 5. Effect of elevating $\mathrm{Ca}^{2+}$ concentration. The ganglion was bathed in $\mathrm{Na}^{+}$-free salines in which $\mathrm{Ca}^{2+}$ concentrations were progressively raised. $A$, In $1.8 \mathrm{~mm}$ (normal) $\mathrm{Ca}^{2+} ; B$, after $5 \mathrm{~min}$ in $5 \mathrm{mM} \mathrm{Ca}^{2+} ; C$, after $4 \mathrm{~min}$ in $10 \mathrm{mM}$ $\mathrm{Ca}^{2+} ; D$, after $4 \mathrm{~min}$ in $20 \mathrm{mM} \mathrm{Ca}^{2+}$. A small bias current held the neuron at the threshold level for plateau production. This was at the same level for $A-$ $C$ but had to be increased slightly in $D$ since threshold shifted to a more depolarized level. Plateaus were triggered on release from $0.1 \mathrm{nA}$ square pulses. 


\section{HN(R,4)}
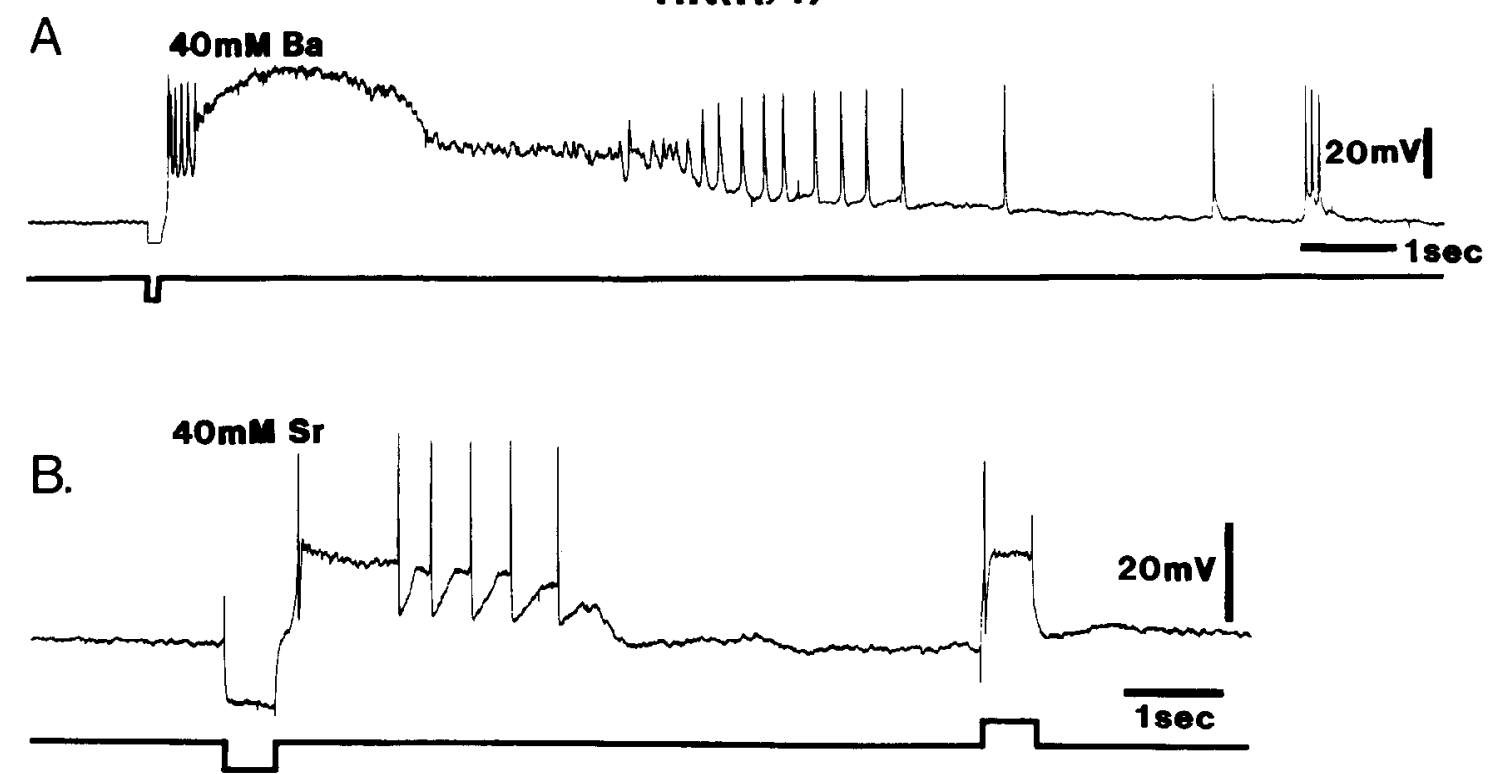

Figure 6. Plateau potentials are supported in the presence of $\mathrm{Ba}^{2+}$ or $\mathrm{Sr}^{2+}$. Preparation bathed by saline in which $40 \mathrm{mM} \mathrm{Ba}^{2+}(A)$ or $40 \mathrm{mM} \mathrm{Sr} r^{2+}$ (B) replaced $\mathrm{Ca}^{2+}$. Pulses were $-0.2 \mathrm{nA}$.

van, 1983), spinal sensory ganglion (Mayer and Westbrook, 1983), and motor neurons (Barrett et al., 1980); amphibian retinal neurons (Attwell and Wilson, 1980; Bader et al., 1982); and lobster stretch-receptor neurons (Edman et al., 1987). These currents - variously given the names $I_{\mathrm{f}}$ (DiFrancesco, 1985), $I_{\mathrm{Q}}$ (Adams and Halliwell, 1982; Edman et al., 1987), or $I_{\mathrm{h}}$ (Attwell and Wilson, 1980) - have been shown to be mediated by a hyperpolarization-activated conductance permeable to $\mathrm{Na}^{+}$and $\mathrm{K}^{+}$. Because the driving force on $\mathrm{Na}^{+}$is very much greater than that on $\mathrm{K}^{+}$in the voltage range of activation, these currents are largely carried by $\mathrm{Na}^{+}$. This class of conductances is susceptible to blockade by low concentrations of $\mathrm{Cs}^{+}$(Brown et al., 1981), whereas $I_{M}$ is sensitive to $\mathrm{Ba}^{2+}$ (Adams et al., 1982).

The restorative sag in membrane potential activated by hyperpolarization of $\mathrm{HN}$ neurons was found, in this study, to depend on the presence of $\mathrm{Na}^{+}$and to be susceptible to blockade by $\mathrm{Cs}^{+}$but not by $\mathrm{Ba}^{2+}$. These properties suggest that the sag may be mediated in HN neurons by currents similar to the hyperpolarization-activated inward currents described above. Insensitivity of the restorative sag in $\mathrm{HN}$ neurons to the $\mathrm{Ca}^{2+}$
Figure 7. Cobalt blocks plateau production but not the ability of $\mathrm{HN}$ cells to spike or hyperpolarization-activated restorative shifts in membrane potential. $A$, Response of an $\mathrm{HN}$ interneuron bathed by normal saline. $B$, Response of the same $\mathrm{HN}$ neuron $3 \mathrm{~min}$ after superfusing the ganglion with normal saline to which $10 \mathrm{~mm} / \mathrm{liter} \mathrm{Co}^{2+}$ had been added. $C$, After $4 \mathrm{~min}$ of washing in $\mathrm{Co}^{2+}$-containing saline, neither action potentials nor plateaus were produced. $D$, Depolarization of the HN interneuron with D. C. Bias current still activated fast action potentials after 8 min in $\mathrm{Co}^{2+}$-containing saline, indicating that cessation of firing was due to a shift in spike threshold to lower membrane potential. However, plateau potentials were no longer observed at any level of membrane potential. All injected pulses were $0.1 \mathrm{nA}$.

\section{$H N(L, 4)$}

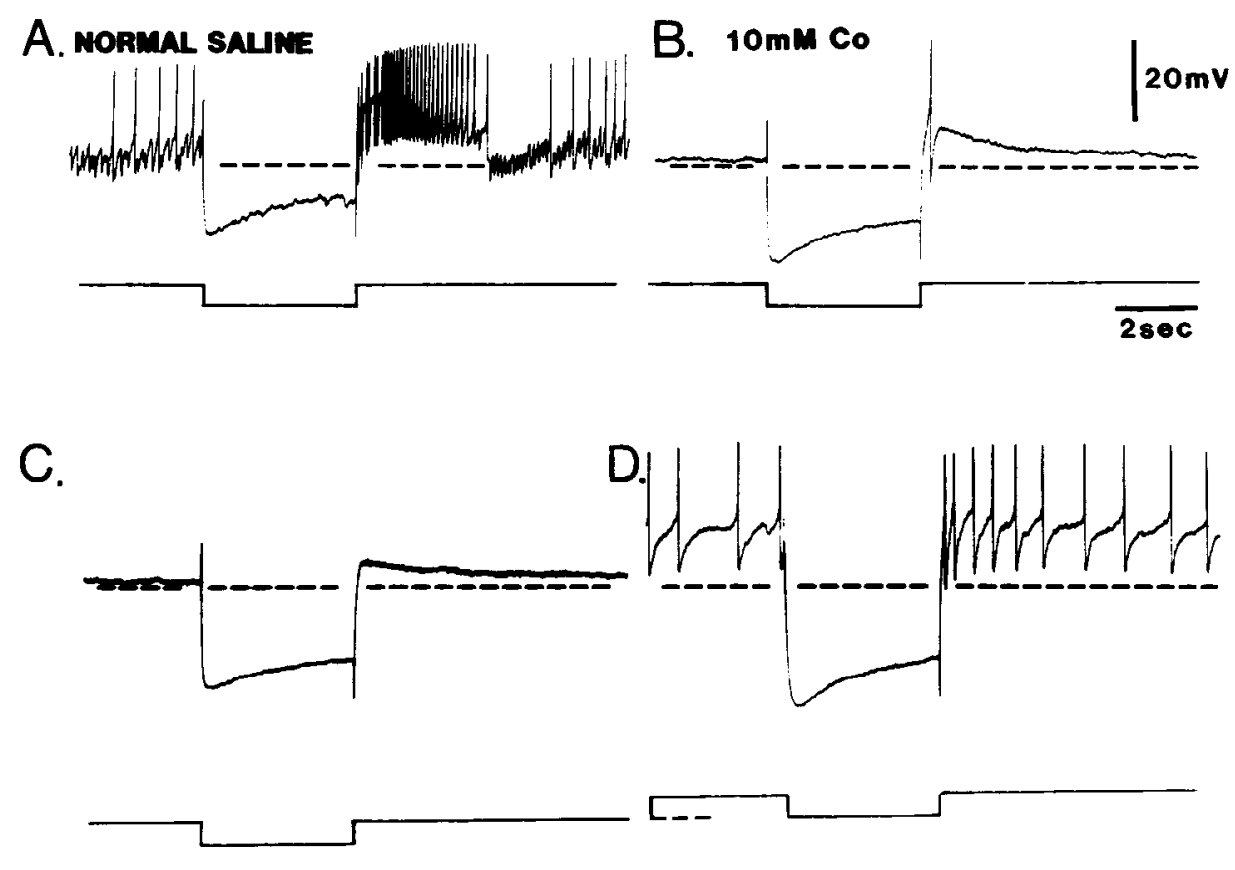




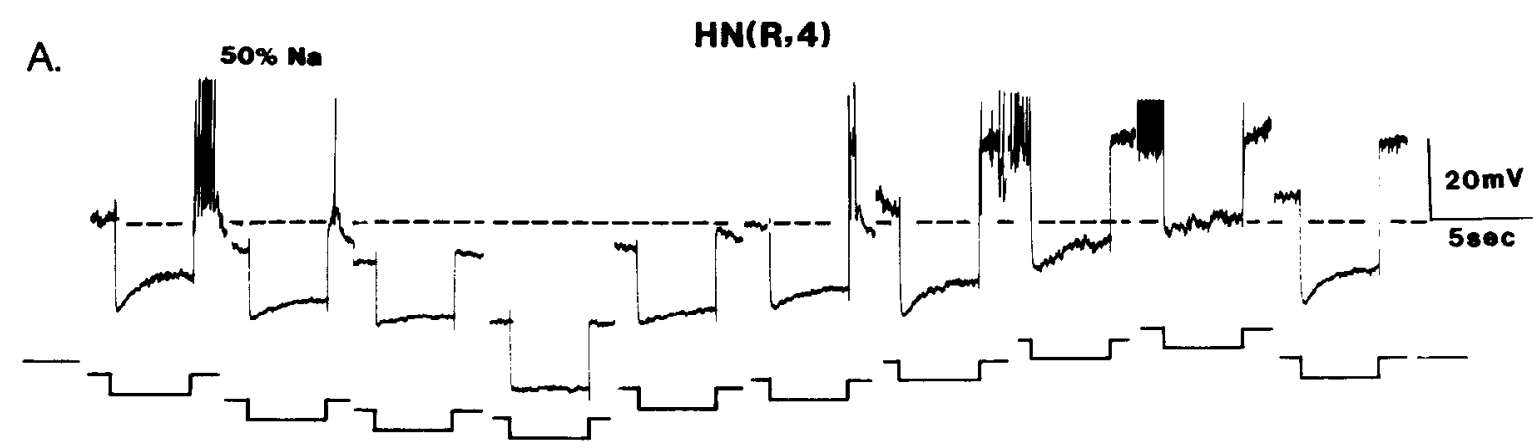

Figure 8. Voltage dependence of restorative shifts in membrane potential was tested by holding an HN interneuron at different potential levels above and below rest with D.C. current while injecting identical $0.2 \mathrm{nA}$ hyperpolarizing square current pulses at each level. The sag in potential during each hyperpolarizing pulse was progressively reduced as the membrane potential of the HN interneuron was hyperpolarized or depolarized away from rest. The preparation was bathed in a saline containing normal $\mathrm{Ca}^{2+}$ and $50 \%$ of normal $\mathrm{Na}^{+}$. Beginning and final solid lines of the current trace indicate zero injected current.
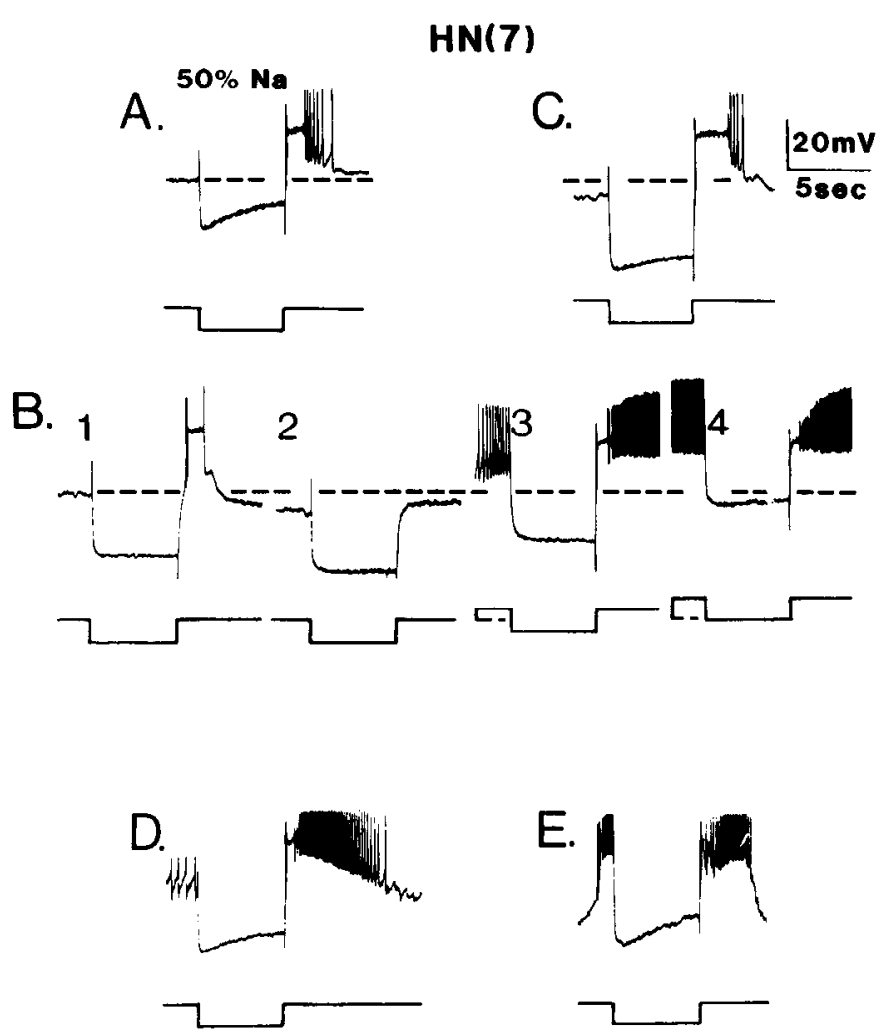

Figure 9. Restorative sags in membrane potential are blocked by $\mathrm{Cs}^{+}$ but not, under similar conditions, by $\mathrm{Ba}^{2+} . A$, Hyperpolarization-activated sags in membrane potential, and plateaus are evident in this $\mathrm{HN}$ (7) interneuron bathed in saline containing normal $\mathrm{Ca}^{2+}$ and $50 \%$ of normal $\mathrm{Na}^{+} . B$, Plateaus and action potentials could be elicited, but restorative sags were absent in the presence of $5 \mathrm{~mm} \mathrm{Cs}^{+} . B 1$, After 40 sec of exposure to $\mathrm{Cs}^{+}$, the sag in membrane potential was absent during the hyperpolarizing pulse. The sag was not restored at more hyperpolarized potentials $\left(B 2,1.5 \mathrm{~min}\right.$ in $\left.\mathrm{Cs}^{+}\right)$or more depolarized membrane potentials $\left(B 3,2\right.$ min in $\mathrm{Cs}^{+} ; B 4,2.5 \mathrm{~min}$ in $\left.\mathrm{Cs}^{+}\right)$. $C$, Eight minutes of washing in $\mathrm{Cs}^{+}$-free saline resulted in a partial recovery of the sag during hyperpolarizing pulses. In another HN (7) interneuron recorded under similar conditions, the sag in membrane potential was evident during hyperpolarizing constant-current pulses both before $(D)$ and 2 min after exposure to $5 \mathrm{mM} \mathrm{Ba}^{2+}(E)$. All current pulses were $0.1 \mathrm{nA}$. channel blockers, $\mathrm{Co}^{2+}$ and $\mathrm{Mg}^{2+}$, reduces the likelihood of another alternative mechanism, i.e., the possible reduction of a $\mathrm{Ca}^{2+}$-activated $\mathrm{K}^{+}$current caused by the hyperpolarization.

Possible contribution of plateau-forming conductances and restorative shifts in membrane potential to normal activity

Depolarizing pulses injected into $\mathrm{HN}$ cells in the range of voltage where the $\mathrm{Na}^{+}$-mediated action potentials are normally generated (near -40 to $-45 \mathrm{mV}$ ) increase the frequency of firing but do not activate any apparent underlying plateau. As HN interneurons are hyperpolarized by their normal synaptic inputs, or by injected currents, the membrane potential is moved into a range subthreshold for the production of fast action potentials but into a range suprathreshold for activation of plateaus. Activation of a plateau-forming $\mathrm{Ca}^{2+}$ conductance on the rising trajectory of membrane potential that follows normal synaptic inhibition could contribute to the formation of a burst by bringing the neuron to threshold for production of $\mathrm{Na}^{+}$-mediated action potentials. Note that due to the overlap in the timing of bursts in the $\mathrm{HN}$ interneurons, the rising phase of any incipient $\mathrm{Ca}^{2+}$-mediated plateau potential would be shunted by the continuing synaptic inhibition and later by the activation of action potentials. $\mathrm{Ca}^{2+}$ is likely admitted to the $\mathrm{HN}$ interneurons during the peak of the normal burst via the conductance that forms the plateau in $\mathrm{Na}^{+}$-free salines. Thus, $\mathrm{Ca}^{2+}$ current could contribute to the sustained depolarization of the $\mathrm{HN}$ cell and the firing of fast spikes in the burst, while at the same time contributing to the release of neurotransmitter both by increases in intracellular $\mathrm{Ca}^{2+}$ and by supporting any other possible voltage dependency that the release process might have (Llinás et al., 1981).

The normal burst of $\mathrm{HN}$ interneurons is terminated by a barrage of IPSPs due to the firing of other HN cells in the network. The hyperpolarization produced by these synaptic inputs moves the membrane potential of the HN interneuron into a range where conductances responsible for the restorative sag in membrane potential are likely to be activated. As we suggest in a separate report (Arbas and Calabrese, 1987), these may play a role in the escape of an HN interneuron from synaptic inhibition, and thus may be important in timing the transition from the inhibited silent phase to the active firing phase in the normal burst cycle. 


\section{References}

Adams, P. R., and J. V. Halliwell (1982) A hyperpolarization induced inward current in hippocampal pyramidal cells. J. Physiol. (Lond.) 324: $62-63$.

Adams, P. R., D. A. Brown, and A. Constanti (1982) M-currents and other potassium currents in bullfrog sympathetic neurones. J. Physiol. (Lond.) 330: 537-572.

Arbas, E. A., and R. L. Calabrese (1987) Slow oscillations of membrane potential in interneurons that control heartbeat in the medicinal leech. J. Neurosci. 7: 3953-3960.

Attwell, D., and M. Wilson (1980) Behavior of the rod network in the tiger salamander retina mediated by membrane properties of the individual rods. J. Physiol. (Lond.) 309: 287-315.

Bader, C. R., D. Bcrtrand, and E. A. Schwartz (1982) Voltage-activated and calcium-activated currents studied in solitary rod inner segments from the salamander retina. J. Physiol. (Lond.) 331: 253-284.

Barrett, E. F., J. N. Barrett, and W. E. Crill (1980) Voltage sensitive outward currents in cat motoneurones. J. Physiol. (Lond.) 304: 251276.

Brown, H. F., D. DiFrancesco, J. Kimura, and S. J. Noble (1981) Caesium: A useful tool for investigating sino-atrial (SA) node pacemaking. J. Physiol. (Lond.) 317: 54P.

Calabrese, R. L. (1979) The roles of endogenous membrane properties and synaptic interaction in generating the heartbeat rhythm of the leech, Hirudo medicinalis. J. Exp. Biol. 82: 163-176.

Calabrese, R. L., and A. R. Maranto (1984) Neural control of the hearts in the leech, Hirudo medicinalis. III. Regulation of myogenicity by heart accessory neurons. J. Comp. Physiol. 154: 393-406.

Calabrese, R. L., and E. L. Peterson (1983) Neural control of heartbeat in the leech, Hirudo medicinalis. In Neural Origin of Rhythmic Movements, A. Roberts and B. Roberts, eds. Symp. Soc. Exp. Biol. 37: 195-221.

Constanti, A., and M. Galvan (1983) Fast inward-rectifying current accounts for anomalous rectification in olfactory cortex neurones. $\mathrm{J}$. Physiol. (Lond.) 335: 153-178.

DiFrancesco, D. (1985) The cardiac hyperpolarizing-activated current, $i_{r}$. Origins and developments. Prog. Biophys. Mol. Biol. 46: 163-183.

Edman, A., S. Gestrelius, and W. Grampp (1987) Current activation by membrane hyperpolarization in the slowly adapting lobster strctch receptor neurone. J. Physiol. (Lond.) 384: 671-690.

Frankenhaeuser, B., and A. L. Hodgkin (1957) The action of calcium on the electrical properties of squid axons. J. Physiol. (Lond.) 137: 218-244.

Hagiwara, S., and L. Byerly (1981) Calcium channel. Annu. Rev. Neurosci. 4: 69-125.

Halliwell, J. V., and P. R. Adams (1982) Voltage clamp analysis of muscarinic excitation in hippocampal neurones. Brain Res. 250: 7192.

Kleinhaus, A. L., and J. W. Prichard (1977) Close relation between TEA responscs and $\mathrm{Ca}$-dependent membrane phenomena of four identified leech neurones. J. Physiol. (Lond.) 270: 181-194.

Llinás, R., I. Z. Steinberg, and K. Walton (1981) Relationship between presynaptic calcium current and postsynaptic potential in squid giant synapse. Biophys. J. 33: 323-352.

Maranto, A. R., and R. L. Calabrese (1984a) Neural control of the hearts in the leech, Hirudo medicinalis. I. Anatomy, electrical coupling and innervation of the hearts. J. Comp. Physiol. 154: 367-380.

Maranto, A. R., and R. L. Calabrese (1984b) Neural control of the hearts in the leech, Hirudo medicinalis. II. Myogenic activity and its control by heart motor neurons. J. Comp. Physiol. 154: 381-391.

Mayer, M. L., and G. L. Westbrook (1983) A voltage-clamp analysis of inward (anomalous) rectification in mouse spinal sensory ganglion neurones. J. Physiol. (Lond.) 340: 19-45.

Nicholls, J. G., and D. A. Baylor (1968) Specific modalities and receptive fields of sensory neurons in the central nervous system of the leech. J. Neurophysiol. 31: 740-756.

Thompson, W. J., and G. S. Stent (1976a) Neuronal control of heartbeat in the medicinal leech. I. Generation of the vascular constriction thythm by heart motor neurons. J. Comp. Physiol. 111: 261-279.

Thompson, W. J., and G. S. Stent (1976b) Neuronal control of heartbeat in the medicinal leech. II. Intersegmental coordination of heart motor neuron activity by heart interneurons. J. Comp. Physiol. 111: 281-307.

Thompson, W. J., and G. S. Stent (1976c) Neuronal control of heartbeat in the medicinal leech. III. Synaptic relations of the heart interneurons. J. Comp. Physiol. 111: 309-333. 